\title{
IMPLEMENTATION AND TESTING OF LOW COST UAV PLATFORM FOR ORTHOPHOTO IMAGING
}

\author{
D. Brucas ${ }^{\text {a, *, J. Suziedelyte-Visockiene }}{ }^{\text {b }}$, U. Ragauskas ${ }^{\text {c }}$, E. Berteska ${ }^{a}$, D. Rudinskas ${ }^{\text {b }}$ \\ ${ }^{a}$ Space Science and Technology Institute, Sauletekio av. 15, LT-10224 Vilnius, Lithuania - dobr@kmti.lt; \\ beflyboy@gmail.com \\ ${ }^{\mathrm{b}}$ Antanas Gustaitis Aviation Institute, Vilnius Gediminas Technical University, Suletekio av. 11, LT-10223 Vilnius, \\ Lithuania - j_visockiene@ hotmail.com; darius.rudinskas@vgtu.lt \\ ${ }^{\mathrm{c}}$ Jonas Zemaitis Military Academy, Silo st. 5, LT-10322 Vilnius, Lithuania - ugniusrag@gmail.com;
}

\section{Commission I, ICWG I/5}

KEY WORDS: Autopilot, Automated flight, Orthophoto imaging, Telemetry

\begin{abstract}
:
Implementation of Unmanned Aerial Vehicles for civilian applications is rapidly increasing. Technologies which were expensive and available only for military use have recently spread on civilian market. There is a vast number of low cost open source components and systems for implementation on UAVs available. Using of low cost hobby and open source components ensures considerable decrease of UAV price, though in some cases compromising its reliability.

In Space Science and Technology Institute (SSTI) in collaboration with Vilnius Gediminas Technical University (VGTU) researches have been performed in field of constructing and implementation of small UAVs composed of low cost open source components (and own developments). Most obvious and simple implementation of such UAVs - orthophoto imaging with data download and processing after the flight.

The construction, implementation of UAVs, flight experience, data processing and data implementation will be further covered in the paper and presentation.
\end{abstract}

\section{INTRODUCTION}

As was mentioned before, in former years unmanned aerial vehicles were quite extensively used for military purposes, which in fact determined high prices for the equipment. Nowadays nonetheless miniaturizing of the electronic equipment and appearance of opens source UAV guidance and control software, allows construction and implementation of low cost civilian UAVs for different purposes (Rysdyk, 2009).

Possibly the least demanding and complicated implementation of UAVs for civilian applications is producing of high resolution orthophoto images (in different possible spectres).

The advantages of implementation of small UAV for orthophoto imaging (comparing to manned aircrafts) are obvious:

1. Low cost of the system and its exploitation;

2. High flexibility of the system;

3. Much higher probability of acquiring the images despite weather conditions - UAVs have the possibility to fly underneath the low cloud layer, which imposes great problems for imaging from high altitude manned aircraft (especially relevant in North European regions such as Lithuania);

4. Possibility of implementation of UAV systems in case the manned aircraft could not be used (in great variety of applications).

Additionally such implementation of small UAVs is least technically complex one - there is no need for direct video streaming, direct aircraft control, precise camera stabilization etc. Therefore, implementation of small UAVs for orthophoto imaging has widely spread all over the world.

Due to these reasons work on development and implementation of UAV for orthophoto imaging is being done in Space Science and Technology Institute (SSTI) in collaboration with Vilnius Gediminas Technical University (VGTU).

It should be noted, that due to low air traffic and absence of regulations forbidding UAV flights beyond visual range of site (often present in other European countries), the environment of civilian implementation of UAVs is quite good in Lithuania. Normally to obtain the permission to work over certain territory, operator of small UAV should inform Civil Aviation Administration of Lithuanian no less than a day before the actual flight, with CAA publishing a NOTAM (no flight zone) over that territory (at certain time and altitude) for UAV work.

\section{CONSTRUCTION OF THE UAV}

The main goal of constructing specialized small UAV, was decreasing the price of it as much as possible, by implementing simple and open source solutions. The main requirement for the construction was to carry a single photo camera of sufficient resolution (12-14 MP).

The airframes implemented are mostly RC model based with minor modifications for fitting specialized components.

\footnotetext{
* Corresponding author.
} 
Airframes ranging from classical ones to the flying wing were tested. Though classical airframes (i.e. having normal fin and stabilizer) implemented for orthophoto imaging show better stability (especially lateral) compared to the wing type (i.e. flying wing), the later ones are far more advantageous from compositional point of view - it is far easier to incorporate the imaging camera in such frame while keeping small size and good aerodynamics (Yanushevsky, 2009). Therefore flying wing airframe show better results in flight distance and endurance in case of same payload compared to the classical airframe.

According to the tests, flying wing of mass up to $1.3 \mathrm{~kg}$ (with payload) and wingspan just over $1 \mathrm{~m}$ have flight endurance of approximately $45 \mathrm{~min}$ and distance of $40 \mathrm{~km}$. While the classical airframe (tested) showed same results only at the total flight mass of approximately $3 \mathrm{~kg}$.

Despite the mentioned advantages of "flying wing" configuration, its great disadvantage (which is very difficult to overcome) is high stall speed, which makes it very risky to operate at low speeds. The high stall speed comes from the aerodynamics of the "flying wing" airframe itself - to increase the angle of attack of the wing (to get higher lift force at low speeds) the elevons has to be inclined upwards, which in turn decreases the curvature of the wing, decreasing its lift force. Therefore aircraft is especially difficult to operate at low speeds making take-off and landing especially difficult. Though the high landing speed has been overcome by implementation of parachute (described further), the take-off is still a challenge ro overcome. According to the tests, launching of the aircraft "from hand" is quite risky procedure (especially if there is no possibility of launching the aircraft against the wind), since during the first seconds of flight aircraft is longitudinally unstable, which has caused many crashes during experiments. Such effect is critical even implementing the motor providing the positive mass/thrust ration (motor/propeller providing thurst greater than the mass of aircraft). The catapult system for the aircraft is under development, but that considerably increases complexity of the UAV system (which is supposed to be as simple as possible).

To decrease the cost commercially available foam based "Skywalker X-5" airframe with electric propulsion was chosen for further testing. Such airframe despite its low price performed extremely well during the real life testing. Additionally Expanded Polyolefin (EPO) construction of the airframe showed itself being very durable and capable of sustaining even serious crashes.

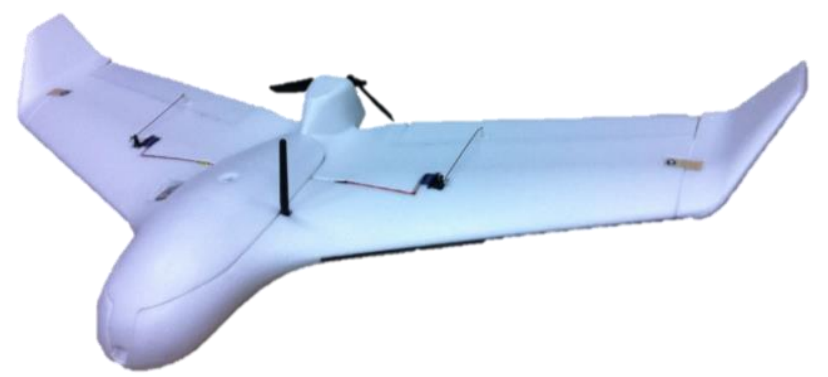

Figure 1. "Flying Wing" airframe implemented

The automatic UAV guidance system implemented (autopilot) is an open source ArduPilot Mega autopilot based on the Arduino embedded system. Though the performances of
Arduino based platform are far not the highest ones (compared to ARM based), it is quite enough for guidance of a small UAV. The ground station implemented is an also open source "Mission Planner", allowing quite simple and "user friendly" guidance of the automated flight.

The open source airplane control system was chosen to decrease the cost (which allows performing of far more tests with different configurations) of and ensure the possibility of simple system changes (which especially important during the testing).

The Arduino based $430 \mathrm{MHz}$ (amateur frequency) $100 \mathrm{~mW}$ telemetry ensures $10 \mathrm{~km}$ reliable data transmission with implementation of a simple pole antenna. Such range $(10 \mathrm{~km})$ is quite enough for performing of most of the tasks of ortophoto imaging by small UAV airplane. Tests have been made with implementation of high gain Yagi antenna for the ground station, in this case the telemetry range was increased up to 15 $\mathrm{km}$ distance. Further increase of flight distance decreased the quality of telemetry considerably due to curvature of the Earth surface, which could be overcome either by increasing the flight altitude (which in turn decreases the image quality considerably) or increasing the height of ground based antenna (which is technically difficult).

The imaging camera used for most of applications - Canon S100, with GPS logging and external custom made power supply and controls. For reliable GPS logging (in the properties of images) an additional external triggering was needed, such triggering is ensured by a special control board, triggering the camera every $2.5 \mathrm{~s}$. The additional control board was needed since (as was mentioned before) Arduino based autopilot did not have enough of computation power to perform both aircraft guidance and camera triggering. Therefore the GPS position of the images is normally imprinted using camera GPS receiver and camera (airplane) attitude is determined by time matching of images time with Ardupilot log data (i.e. attitude at a certain point of time). The camera triggering board is normally activated via telemetry at the point where the imaging should be started.

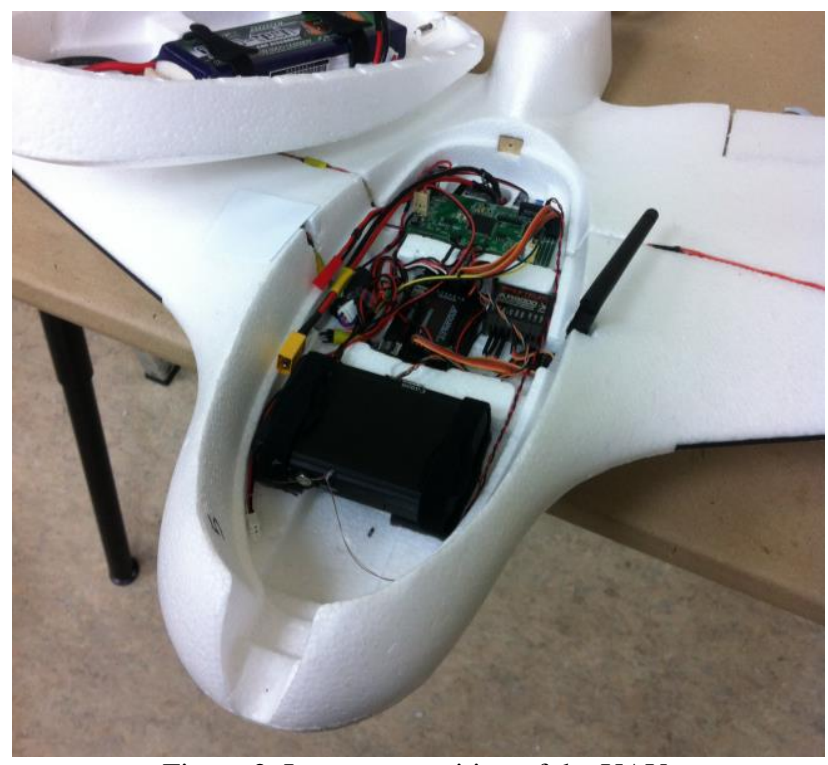

Figure 2. Inner composition of the UAV

It is foreseen that with switching from Arduino to ARM based autopilots (having much higher computational possibilities), all 
of the camera control duties could be performed by autopilot processor.

To protect the camera and inner components of the airplane form the snow, sand and dew during the landings, a special camera hole closing mechanism is installed on the belly of the aircraft. This is absolutely necessary in case the airplane is implement in the snowy winter conditions (which is a case in Lithuania). The camera hole is normally closed before the landing of aircraft, and operated by autopilot. The experiments proved, that implementation of the aircraft without the camera cover is especially problematic in winter conditions, since snow accumulates in the camera hole during the landing (especially in case of belly landing and strong wind, dragging the parachute), cleaning the camera of the snow takes long time and decreases the quality of images during consequent flights.

Since belly landing of the aircraft was not the suitable option due to the high stall speed (disadvantage of flying wing mentioned before) and therefore high landing speed combined with difficulties in finding the suitable open space landing places close to work sides in Lithuania, the decision was made to implement the custom made parachute for soft landing. The parachute, while adding minimal mass and complexity to the aircraft allows its precise landing within the radius of $10 \mathrm{~m}$ from the operator. Such landing method allows soft landing in high grass, bushes, on pavements etc., which is especially important in urban areas or in European landscape (with lots of natural or man built structures).

Several types of parachutes have been testes ("Rocketman" parachute deployed is shown in Fig. 3), with the best results (price/efficiency/un-deployed volume) being shown by custom made para-sheet of $1.2 \mathrm{~m}$. The descent rate with such parachute is in the range of $3-5 \mathrm{~m} / \mathrm{s}$, which is sufficient for landing on the hard structures (like concrete, building, rocks etc.), which was repeatedly demonstrated during the testing.

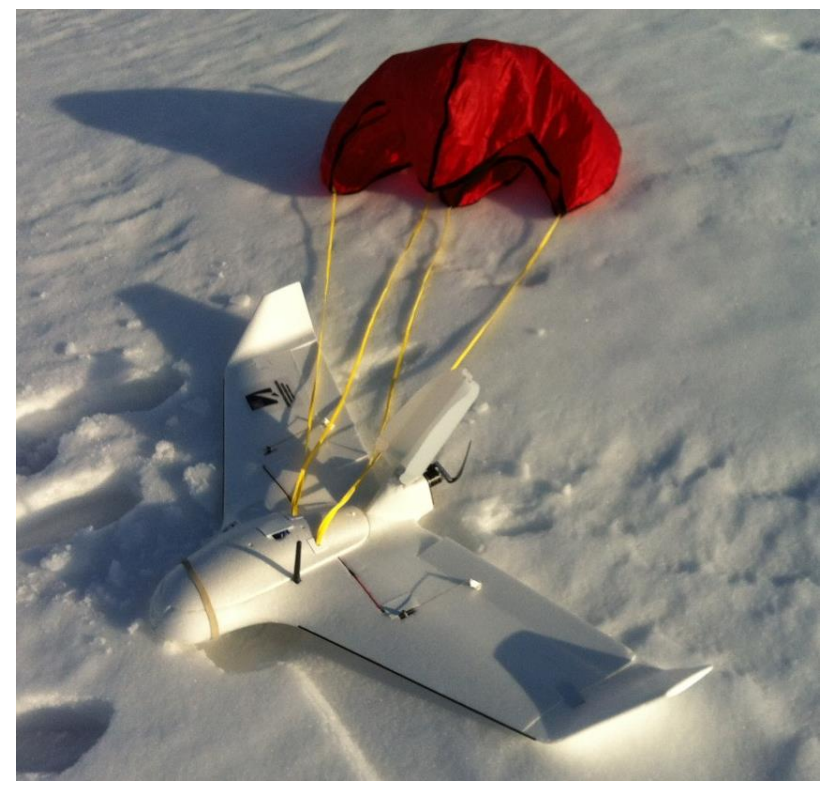

Figure 3. Parachute of the UAV exposed

The parachute deployment implemented - is simplest possible, with opening of the parachute lid at the certain point and aerodynamic forces (due to speed of the aircraft) deploying the parachute itself. The need for the parachute landing system became especially evident at the point when flights had to be performed at urban (taking-off and landing form the small stadiums) and forest (taking-off and landing at the tree-cut areas) areas.

Such arrangement of equipment allows reliable implementation of UAV in up to $10 \mathrm{~km}$ (or $15 \mathrm{~km}$ in case of loose of a telemetry data) range, with a flight endurance of 45-60 m. the Flight altitude of $100-250 \mathrm{~m}$ resulting in the imaging resolution of approximately $3-5 \mathrm{~cm}$. The usual orthophoto imaging flight covers $0,5-2 \mathrm{~km}^{2}$ (though more is possible), depending on the resolution needed and weather conditions.

The flights are usually performed in a fully automated mode, with an automated takeoff (from hand) and parachute landing, nevertheless the first takeoff is usually performed in manual mode to determine the properties of the operational field. Basing on flight experience reliable orthophoto images can be obtained at the wind of up to $10 \mathrm{~m} / \mathrm{s}$ (though the stability of images rapidly decrease in higher winds, thus implying the need of decreasing the distance between the flight passes). It was determined that rain, snow, fog, darkness has little impact on UAV flight performances, with only limitation of sufficient visibility for orthophoto imaging.

The icing of aircraft surfaces is not a great problem even at extreme low temperatures since the flights are usually performed well underneath the cloud pad. Similarly the weather temperatures do not impose the problems on UAV performances (system was tested at temperatures from +30 to 20), partly due to inner heating from the electric motor battery (generating enough heat while discharging), with flight time even increased due to higher density of the air (and higher lifting force due to that) at cold weather. The main problem with operating the aircraft at low temperatures was the discharging (or not sufficient charging) of the battery of camera, which was successfully overcome by providing the energy needed for camera from the main aircraft battery.

\section{ORTOPHOTO IMAGING}

As was mentioned before, ortophoto imaging is normally performed from altitude of 100 to $250 \mathrm{~m}$, depending on the resolution needed. Nonetheless test of flying at the altitude of $50 \mathrm{~m}$ above the ground were successfully performed, proving that such low level flights are safe enough in the known environment (no mountains, no high antennas, towers etc.). It should be noted, that low level flights were mostly tested by the request from Lithuanian military forces, to test the possibilities of determination of enemy activities.

The normal flight at an altitude of 100 to $250 \mathrm{~m}$ with the $12 \mathrm{MP}$ Canon S100 camera produce the images of resolution of $3-5 \mathrm{~cm}$ per pixel, which is quite sufficient for high resolution ortophoto images.

During the testing it was also noted that, due to relatively high speed of the aircraft of "flying wing" configuration, the winds of up to $10 \mathrm{~m} / \mathrm{s}$ have little impact on the images quality. Generally the aircraft can be successfully operated (with decresed quality of images) at the winds of up to $15 \mathrm{~m} / \mathrm{s}$, the main danger of the high wind being aircraft flying "backwards".

It should be also noted, that more stable, low speed classical airframes showed worst resistance to the winds. During experiments, the classical airframes could be operated at the 
wind of up to $7 \mathrm{~m} / \mathrm{s}$. That being additional reason for "flying wing" configuration implementation.

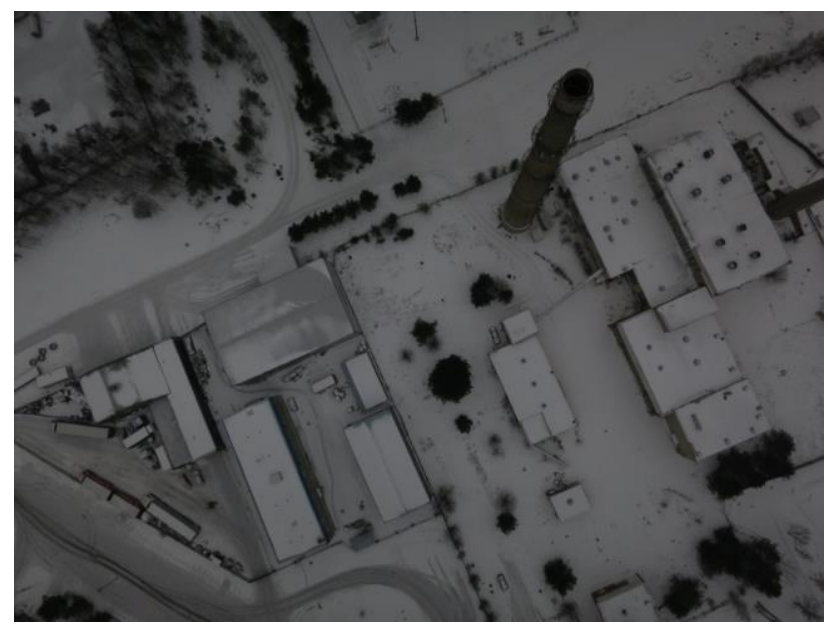

Figure 4. Image taken from altitude of $200 \mathrm{~m}$

Despite the lower stability of the "Flying Wing" platform (which is clearly noticeable from the images and flight pattern) compared to the classical airframe, the quality of the images obtained is quite sufficient for the reliable ortophoto mosaicking of the specified objects.

During the tests it was also determined, that clouds have very little impact on the quality of images, since absolutely most of the flights are performed well under cloud pad, which makes is possible to obtain good images even during cloudy day (which would not be possible implementing normal aviation). The main reasons of decrease of the quality of images are rain, snow and fog, unfortunately those phenomena cannot be easily overcome implementing visual cameras.

The camera implemented (Canon S100) was calibrated using TCC software (Germany), with calibration data used later during image processing (Suziedelyte-Visockiene, et al., 2009). As the camera needs to be focussed to eternity during all the imaging process (which cannot be done with camera "as is"), special script is uploaded to camera, setting the focusing to eternity every time the camera is on (Alshawabkeh, 2009). The images are downloaded from the airplane camera after the flight via USB port, and those can be immediately placed on the map to check quality of obtained data (Shariat, et al., 2008).

Multiple software was tested for image processing and image mosaicking, with different level of suitability determined. Generally the simple software (like Autopano Giga) is implemented for "in field" mosaicking of images to get preliminary results and determine the general quality of imaging. And some more sophisticated software (like Photomod or Envi) for accurate orthophoto mosaicking and precise images geo referencing (Carstensen, 2001).

Together with the mosaicked orthophoto images the 3D Digital Terrain Model (DTM) is sometimes produced from the images, allowing determination of precise enough height features of the object of interest. Usually DTM is being produced in parallel with orthophoto moasaic and can be used as supplement (or source of additional information) to it (Fig. 7).

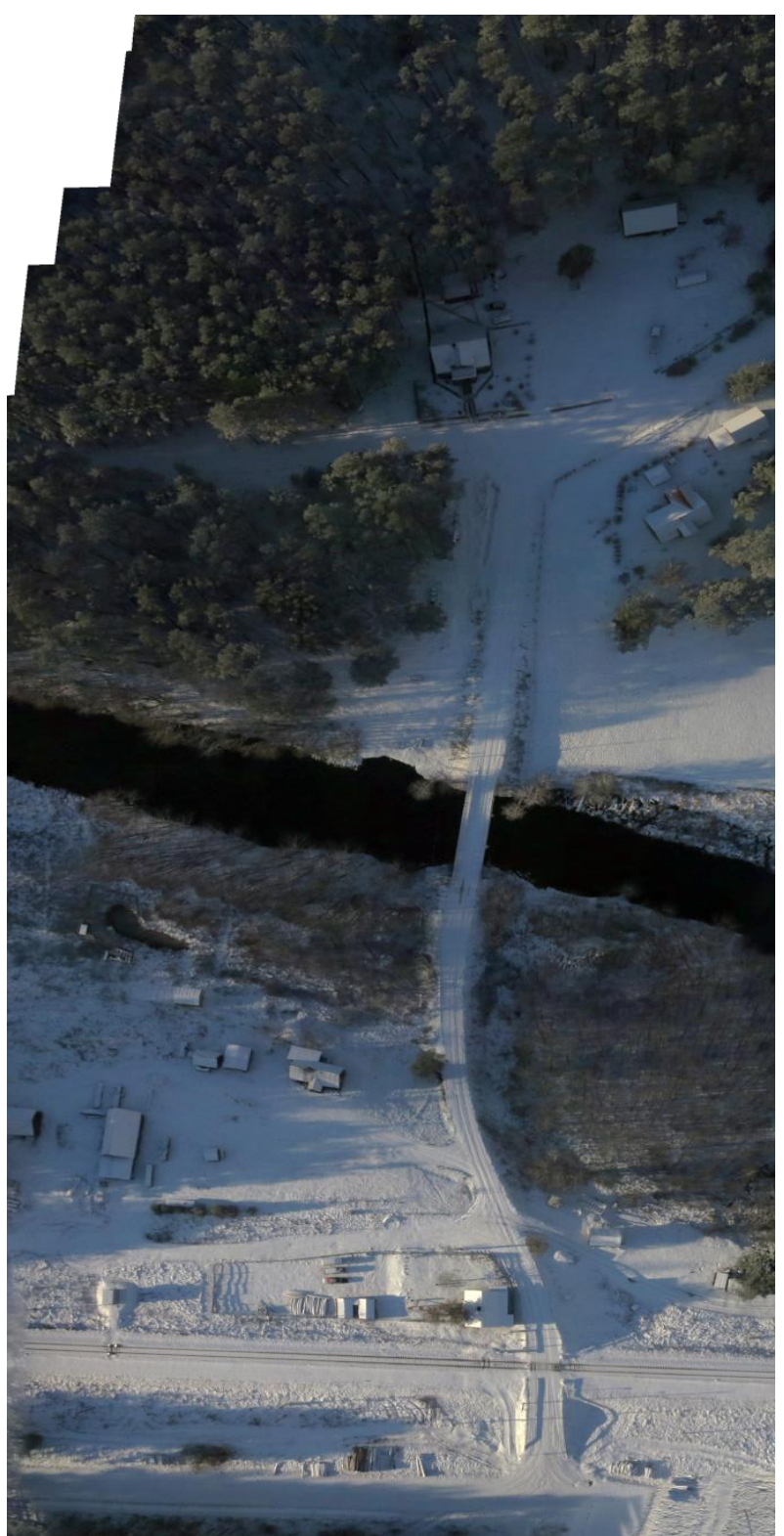

Figure 5. Ortophoto mosaic of the object

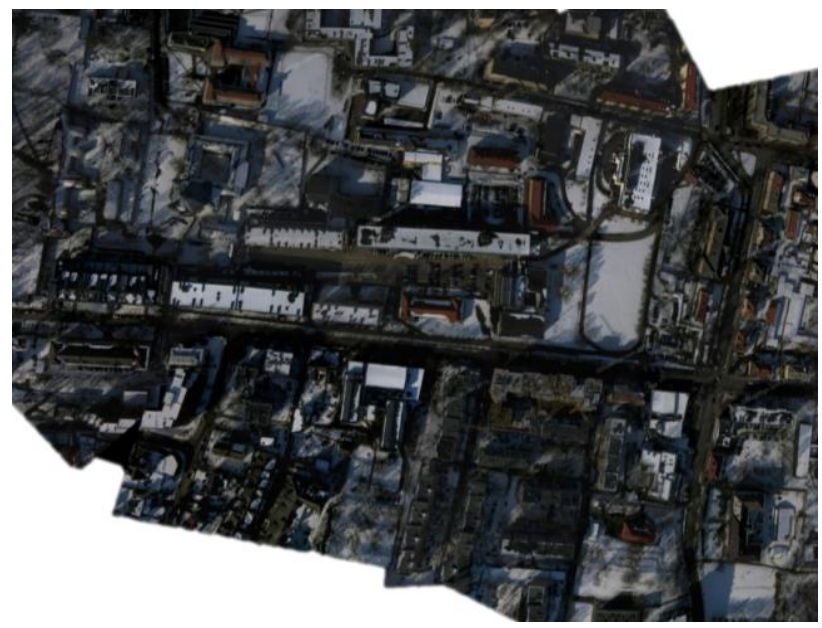

Figure 6. Ortophotomosaic of the city region 


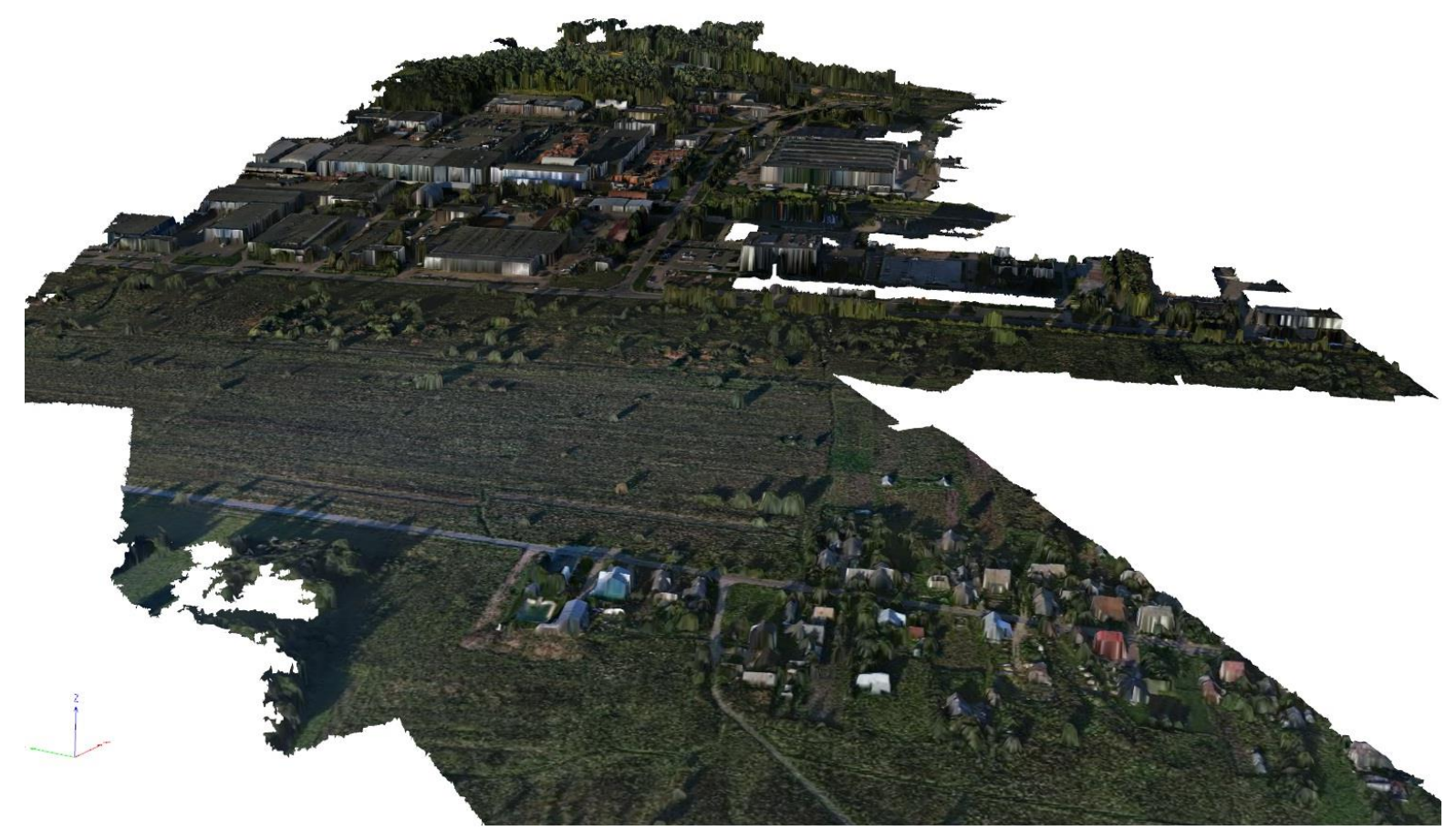

Figure 7. 3D model of the object

\section{CONCLUSIONS}

- Simple low cost but fully functional UAV for ortophot imaging can be built from opensource and cheap commercially available components;

- Having in mind the size, composition and aerodynamic features, the best airframe for orthophoto imaging (for small UAVs) is the Flying Wing configuration.

- Some special protection (like camera cover) and soft landing (like parachute) equipment is essential for implementation of UAV in hostile environment (snow, dew, high grass, bushes, etc.);

- The quality of obtained orthophoto images is quite sufficient for high resolution images mosaic and Digital Terrain Models.

\section{REFERENCES}

Alshawabkeh, Y., 2009. A New True Ortho-Photo Methodology For complex archaeological application. Archaeometry, University of Oxford, t 111, Nr.10, p.14.

Carstensen, J. M., 2001. Image Analysis, Vision and Computer Graphics. 1st edition, Informatics and Mathematical Modeling. Technical University of Denmark.

Rysdyk, R., 2009. UAV Path Following for constant line-ofsight. In: 2nd AIAA .Unmanned Unlimited. Systems,Technologies, and Operations Aerospace, Land, and Sea Conference, Paper \#6626, San-Diego, CA.

Shariat, M., Azizi, A., Saadatseresht, M., 2008. Analysis and the solutions for generating a true digital ortho photo in close range photogrammetry. In: The International Archives of the Photogrammetry, Remote Sensing and Spatial Information Sciences. Vol XXXVII, Part B4, Beijing, pp. 439-442.
Suziedelyte-Visockiene, J., Brucas, D., 2009. Influence of digital camera errors on pthe hotogrammetric image processing. Geodezija ir kartografija. Vilnius: Technika, t. 35, Nr. 1, pp. 29-33.

Yanushevsky, R., 2009. Missile Guidance. In: AIAA Guidance, Navigation, and Control Conference, Chicago, IL.

\section{ACKNOWLEDGEMENT}

This work is funded by the Lithuanian Science Council under the project No. MIP-089/2012. 